\title{
Pola Perilaku Hidup Bersih dan Sehat pada Tatanan Rumah Tangga di Kota Surabaya, Indonesia
}

\section{The Pattern of Clean and Healthy Living Habits in Households in the City of Surabaya, Indonesia}

\author{
Rena Azizul Fadila*1, Riris Diana Rachmayanti ${ }^{2}$
}

\begin{abstract}
ABSTRAK
Latar Belakang: salah satu program yang dapat digunakan untuk memampukan anggota keluarga dalam pelaksanaan PHBS adalah melalui program PHBS rumah tangga. Dengan program PHBS ini, keluarga akan turut berperan aktif pada gerakan kesehatan di masyarakat. Hasil survey berdasarkan data Dinas Kesehatan Kota Surabaya tahun 2018 menunjukkan sebanyak 68,74\% rumah tangga di Kota Surabaya telah menerapkan Perilaku Hidup Bersih dan Sehat (PHBS), sedangkan target dari Kementrian Kesehatan sebanyak 70\%.

Tujuan: Penelitian ini bertujuan untuk menganalisis hubungan pengetahuan, dan sikap masyarakat di tatanan rumah tangga dalam menerapkan perilaku hidup bersih dan sehat sebagai salah satu upaya dalam peningkatan derajat kesehatan masyarakat.

Metode: Penelitian ini menggunakan metode analitik, desain yang digunakan adalah korelasional, dan pendekatan yang digunakan menggunakan pendekatan cross-sectional. Penelitian ini dilakukan pada Januari 2020 di RW 9 Kelurahan Ujung. Populasi penelitian ini adalah ibu yang memiliki bayi usia 0-24 bulan sebanyak 85 orang. Penentuan sampel dalam penelitian ini dengan metode simple random sampling yaitu sebanyak 71 orang. Pengetahuan dan sikap merupakan variabel independen, sedangkan perilaku hidup bersih dan sehat merupakan variabel dependen. Pengolahan data dapam penelitian ini menggunakan uji Spearman.

Hasil: Penelitian ini menunjukkan hasil bahwa $p$ value pada variabel pengetahuan adalah $0,000<\alpha(0,05)$ dengan correlation coefficient $\mathrm{p}=0,678$, sehingga dapat diartikan bahwa terdapat hubungan dengan keeratan yang kuat antara pengetahuan dengan PHBS. Sedangkan $p$ value pada variabel sikap adalah p $0,000<\alpha(0,05)$ dengan correlation coefficient $\mathrm{p}=0,705$ yang menunjukkan adanya hubungan dengan keeratan yang kuat antara sikap dengan PHBS.
\end{abstract}

Kesimpulan: Pengetahuan keluarga merupakan faktor utama pada penerapan PHBS di tatanan rumah tangga. Perlu adanya kerja sama antara lintas sektor untuk meningkatkan kegiatan penyuluhan dan emo demo guna meningkatkan pengetahuan masyarakat.

Kata kunci: PHBS, Perilaku, Rumah Tangga, Pengetahuan, Sikap

\section{ABSTRACT}

Background: Household PHBS is a program to enable family members to know and be able to implement PHBS and have an active role in the health movement in the community. Data from the Surabaya City Health Office in 2018, the results of the survey showed that the behavior of clean and healthy living (PHBS) in the household structure in the City of Surabaya in 2018 was 68.74\%. This figure is still below the Ministry of Health's target of $70 \%$.

Objectives: This study aims to analyze the relationship between knowledge and attitudes of the community in the household structure in implementing clean and healthy living habits as an effort to improve the degree of public health. 
Methods: This research is an analytical study and the design used in this study is correlational using a cross sectional approach. This research was conducted in January 2020 at RW 9 Kelurahan Ujung. The population of this research is 85 mothers who have babies aged 0-24 months. Determination of the sample in this study using simple random sampling method, as many as 71 people. The independent variable in this study is knowledge and attitudes related to PHBS, the dependent variable is the behavior of a clean and healthy life. Then the data is processed data using a computer application with the Spearman test.

Results: This study shows that the $p$ value on the knowledge variable is $0.000<\alpha(0.05)$ with a correlation coefficient of $p=0.678$, so it can be interpreted that there is a strong relationship between knowledge and PHBS. While the $p$ value on the attitude variable is $p 0.000<\alpha(0.05)$ with the correlation coefficient $p=0.705$ which indicates a very strong relationship between attitudes and PHBS. .

Conclusions: In implementing PHBS in household arrangements, the main factor is family knowledge. There is a need for cross-sector cooperation to increase outreach and emo demonstrations in order to increase public knowledge.

Keywords: PHBS, Behavior, Household, Knowledge, Attitude

\author{
*Koresponden: \\ rena.azizul.fadila-2018@fkm.unair.ac.id \\ Rena Azizul Fadila \\ Departemen Kesehatan Lingkungan, Fakultas Kesehatan Masyarakat, Universitas Airlangga, Kampus C \\ Mulyorejo, 60115, Surabaya, Jawa Timur, Indonesia
}

\title{
PENDAHULUAN
}

Definisi Kesehatan menurut Undang-Undang Republik Indonesia Nomor 36 Tahun 2009 adalah sebuah keadaan dimana seseorang dalam kondisi sehat baik dari segi fisik, sosial, mental serta spiritual sehingga dapat produktif secara sosial dan ekonomis. Dalam Pancasila dan UUD RI tahun 1945 disebutkan bahwa Kesehatan merupakan hak asasi manusia, dimana salah satu cita cita dari bangsa Indonesia adalah Kesehatan yang sejahtera dapat terwujud (UU RI, 2009).

Adapun empat faktor yang mempengaruhi derajat kesehatan menurut H.L Blum. Faktor yang pertama menyebutkan bahwa faktor lingkungan dapat mempengaruhi Kesehatan. Faktor lingkungan yang dimaksud adalah lingkungan fisik, budaya, sosial maupun politik. Faktor yang kedua adalah faktor perilaku masyarakat secara perorangan. Faktor ketiga yang dapat mempengaruhi kesehatan adalah pelayanan Kesehatan. Sedangkan faktor terakhir menurut H.L Blum adalah faktor genetik atau keturunan. Suatu kondisi atau lingkungan yang optimal akan mewujudkan status kesehatan yang terbaik. Derajat kesehatan yang terbaik dapat diwujudkan salah satunya dengan pembangunan kesehatan nasional agar setiap penduduk sadar, mau, serta mampu untuk hidup lebih sehat (Adnani, 2011).

Becker mengembangkan konsep sehat yang telah dibuat oleh Bloom sebelumnya. Dimana konsep tersebut menyebutkan terdapat tiga domain pada perilaku sehat. Domain yang pertama adalah pengetahuan akan Kesehatan. Domain yang kedua adalah sikap terhadap perilaku kesehatan, dan domain yang ketiga adalah tindakan dari kesehatan itu sendiri. Manfaat dari ketiga domain tersebut adalah agar individu sadar akan tingkat perilaku sehat mereka (Notoatmodjo, 2014).

Pengetahuan Kesehatan merupakan hal-hal yang individu pahami tentang cara memeliharan dan meningkatkan Kesehatan dari individu tersebut. Sikap mengenai kesehatan merupakan respon individu terhadap tindakan kesehatan, misalnya penilaian individu akan hal-hal yang berkaitan dengan cara menjaga kesehatan. Sedangkan tindakan atau praktik Kesehatan merupakan tindakan yang dilakukan secara langsung meliputi keseluruhan kegiatan untuk mendapatkan perilaku sehat (Notoatmodjo, 2014).

Perilaku adalah hal yang kompleks. System kebudayaan, termasuk didalamnya norma dan nilai merupakan hal yang mempengaruhi perilaku. Cerminan tentang sesuatu yang dirasa baik ataupun buruk adalah yang dimaksud sistem nilai. Terdapat dua bagian pada norma yakni norma sosial dan norma hukum. Norma sosial merupakan aturan yang tidak tertulis, sedangkan norma hukum merupakan aturan yang tertulis. Perilaku seorang individu juga berkaitan dengan ekonomi serta hal-hal lain yang dapat mendukung sebuah perilaku (Kementerian Kesehatan RI, 2011).

Salah satu upaya untuk menciptakan perilaku sehat dapat dilakukan melalui Program Perilaku Hidup Bersih dan Sehat (PHBS) yang dilakukan secara teratur dan tertib. PHBS merupakan perilaku yang harus dilakukan secara sadar oleh sebuah keluarga, sehingga mereka dapat menjaga dirinya sendiri agar tetap sehat serta berperan aktif dalam masyarakat terkait kegiatan Kesehatan. Tujuan dari PHBS di rumah tangga adalah agar anggota rumah tangga mampu dan tahu tentang perilaku hidup bersih dan sehat sehingga menerapkan perilaku tersebut dan dapat berperan aktif di masyarakat terkait gerakan hidup bersih dan sehat (Kementerian Kesehatan RI, 2016). 
Rumah tangga yang sehat memiliki beberapa manfaat, diantaranya keluarga yang sehat akan menumbuhkan anak-anak yang cerdas dan sehat. Keluarga yang sehat akan cenderung terhindar dari masalah Kesehatan, sehingga produktivitas dalam keluarga akan meningkat. Anak yang hidup dalam keluarga yang sehat akan tumbuh menjadi anak yang sehat serta gizi pada anak tersebut akan tercukupi (Kementerian Kesehatan RI, 2011).

Terdapat sepuluh indikator dari PHBS pada tatanan rumah tangga. Indicator ini dapat digunakan sebagai rujukan identifikasi kesuksesan praktik PHBS dalam tatanan rumah tangga (Kementerian Kesehatan RI, 2016). Sepuluh indikator dari PHBS antara lain adalah:

1. Proses persalinan dibantu oleh tenaga kesehatan. Tenaga Kesehatan yang dapat menolong proses persalinan meliputi bidan, dokter atau paramedis lainnya. Tujuan dari indikator pertama ini adalah menjaga keselamatan ibu dan bayi dari risiko infeksi dan bahaya lain.

2. Wajib memberikan ASI eksklusif. Bagian penting dalam PHBS adalah kesadaran dalam mengetahui manfaat ASI untuk bayi usia 0 sampai 6 bulan.

3. Menimbang bayi serta balita dengan rutin di posyandu. Tujuan dari penimbangan bayi dan balita adalah agar dapat dengan mudah memantau tumbuh kembang anak serta memantau pemberian imunisasi pada anak. Salah satu cara untuk mendeteksi dini kasus gizi buruk dengan melakukan penimbangan bayi secara rutin.

4. Sebelum dan sesudah makan selalu dibiasakan untuk mencuci tangan menggunakan air yang mengalir dengan sabun. Mencuci tangan merupakan sebuah langkah agar kebersihan terjaga sehingga penularan penyakut dapat dicegah karena terbebas dari kuman.

5. Penggunaan air bersih. Untuk menjalani kehidupan yang lebih sehat maka dianjurkan untuk menggunakan air bersih sebagai pemenuhan kebutuhan dasar.

6. Penggunaan jamban yang sehat pada setiap rumah. Salah satu prasarana sanitasi yang harus dimiliki setiap rumah tangga adalah jamban. Keguanaannya adalah sebagai unit pembuangan air dan kotoran.

7. Memberantas jentik nyamuk. Pembersihan jentik nyamuk merupakan sebuah upaya agar siklus hidup nyamuk dapat terputus sehingga dapat mencegah berbagai macam penyakit.

8. Konsumsi berbagai jenis sayuran dan buah dengan seimbang. Tubuh yang sehat secara maksimal adalah terpenuhinya kebutuhan gizi secara seimbang seperti serat, mineral, dan vitamin.

9. Melakukan aktivitas fisik setiap hari. Aktivitas fisik yang dapat dilakukan adalah kegiatan olahraga, dapat berupa gerakan yang dapat mengeluarkan tenaga.

10. Menghindari asap rokok. Berbagai macam penyakit dapat dialami oleh perokok pasif, hal ini dapat berasal dari perokok aktif.

Rumah tangga yang memiliki balita apabila terpenuhi sejumlah enam indikator atau lebih adalah termasuk rumah tangga yang memenuhi kriteria PHBS yang baik. Sedangkan apabila rumah tangga tidak mempunyai balita dapat digolongkan rumah tangga dengan PHBS yang baik apabila telah memenuhi minimal 5 indikator. (Kusumawardani, 2018). Pelaksanaan program PHBS adalah salah satu bentuk upaya meningkatkan keahlian individu, keluarga, dan masyarakat berupa ilmu. Ilmu tersebut bisa didapat melalui berbagai media, seperti penyiaran berita dan pendidikan Kesehatan. Sistem advokasi, bina suasana, dan melancarkan pemberdayaan pada masyarakat dapat meningkatkan perubahan perilaku kesehatan. Perilaku kesehatan yang dimaksud adalah pengetahuan, sikap, dan tindakan kesehatan (Wati and Ridlo, 2020).

Survey Demografi dan Kesehatan Indonesia 2017 menyajikan data bahwa persalinan ibu yang ditolong oleh tenaga kesehatan yang berkompeten sebanyak 91\%. Pada pemberian ASI eklusif kepada anak usia 0 sampai 6 bulan sebanyak 52\%. Penimbangan bayi meliputi pemantauan apakah anak mendapatkan imunisasi lengkap, pada data ini menyajikan sebanyak 59\% anak mendapatkan imunisasi lengkap. Perilaku cuci tangan dapat terealisasi saat individu memiliki sarana dan prasarana, pada SDKI 2017 didapatkan sebanyak 93\% rumah tangga menyediakan sabun dan air tempat cuci tangan. Penggunaan air bersih didapatkan sebanyak $75 \%$ rumah tangga memiliki akses pada sumber air minum yang layak. Rumah tangga yang memiliki sanitasi yang layak sebanyak $80 \%$ rumah tangga. Penggunaan tembakau atau perilaku merokok pada orang Indonesia menurut SDKI 2017 didapatkan sebanyak $72 \%$ pria merokok dan 2\% wanita merokok (BKKBN et al., 2018).

Hasil dari laporan nasional Riset Kesehatan Dasar 2018, menunjukkan data bahwa proporsi penolong persalinan dengan kualifikasi tertinggi di Provinsi Jawa Timur sebesar 97,4\% (Badan Penelitian dan Pengembangan Kesehatan, 2019a). Pemberian ASI dalam 24 jam pada bayi 0-5 bulan di Provinsi Jawa Timur sebesar 71,46\%. Proporsi penimbangan berat badan pada anak balita yang sesuai standar di Provinsi Jawa Timur sebesar 69,0\%. Pada penimbangan balita juga memantau imunisasi dasar pada balita, pada Riskesdas ditemukan sebesar 69,2\% imunisasi dasar lengkap di Provinsi Jawa Timur. Perilaku cuci tangan dengan benar di Jawa Timur sebesar 54,3\%. Penggunaan air per orang per hari kurang dari 20 liter sebesar 2,1\% dan lebih dari 20 liter sebesar 97,9\%. Perilaku buang air besar yang benar pada masyarakat Jawa Timur sebesar $86,9 \%$. Pemberantasan sarang nyamuk di Jawa Timur yang menerapkan 3M sebanyak 39,9\%, sedangkan yang 3M Plus sebanyak 28,9\%. Proporsi konsumsi buah dan sayur kurang dari 5 porsi per hari pada masyarakat Jawa Timur sebesar 93,9\%. Aktivitas fisik kurang dari 150 menit seminggu ditemukan sebesar 26,5\%. Perilaku merokok di dalam ruangan dan gedung pada masyarakat Jawa Timur sebesar 81,8\% (Badan Penelitian dan Pengembangan Kesehatan, 2019b). 
Hasil survei yang dilakukan di Kota Surabaya mengenai PHBS dalam tatanan rumah tangga sebesar 68,74\%. Presentase rumah tangga yang melakukan PHBS menurut Kecamatan dan Puskesmas didapatkan hasil bahwa Kecamatan Semampir dan Puskesmas Sawah Pulo yang dipantau sebanyak 21,14 dan yang melakukan PHBS sebanyak 61,39\%. Rencana Pembangunan Jangka Menengah Daerah (RPJMD) Kota Surabaya 2016-2021 menghasilkan sebuah ketetapan berupa kebijakan tentang pembanagunan Kesehatan. Sasaran yang dituju pada bidang kesehatan ini adalah peningkatan status gizi serta derajat Kesehatan masyarakat melalui upaya kesehatan dengan memberdayakan masyarakat. Upaya ini dilakukan dengan perlindungan keuangan serta pelayanan Kesehatan yang merata (Dinas Kesehatan Kota Surabaya, 2019).

Tujuan dari penelitian ini adalah untuk melihat hubungan antara pengetahuan dan sikap dengan PHBS sebagai upaya untuk meningkatkan derajat kesehatan. Terutama terhadap hubungan PHBS pada masyarakat khususnya Kelurahan Ujung, Kecamatan Semampir, Kota Surabaya.

\section{METODE}

Penelitian ini memiliki jenis rancangan berupa penelitian analitik, dimana dilakukan analisis hubungan dari dua variabel atau lebih. Penentuannya melalui uji statistic. Penelitian ini menggunakan desain korelasi dengan pendekatan cross-sectional. Tujuannya adalah melihat hubungan antar variabel. Penentuan variabel berbas serta variabel terikan dilakukan satu kali (Dharma, 2011).

Penelitian ini dilaksanakan pada bulan Januari 2020. Populasi penelitian yaitu seluruh ibu yang mempunyai bayi dengan usia 0-24 bulan atau bayi usia $\leq 2$ tahun (baduta). Hasil data yang diperoleh dari Puskesmas Sawah Pulo jumlah baduta tercatat sebanyak 85 orang di RW 9, Kelurahan Ujung, Kecamatan Semampir, Surabaya. Sampel ditentukan melalui metode simple random sampling yaitu pengambilan sampel secara acak, yaitu setiap anggota populasi memiliki kesempatan yang sama untuk dimasukkan ke dalam sampel. Perhitungan sampel menggunakan rumus lemeshow, kemudian didapatkan sampel sebanyak 71 sampel.

Instrumen yang digunakan untuk mengambil data dalam penelitian ini adalah menggunakan kuesioner. Kuesioner tersebut bertujuan untuk melihat karakteristik responden seperti umur, tingkat pendidikan, dan pekerjaan. Kuesioner juga melihat tingkat pengetahuan, sikap, dan PHBS di lingkungan keluarga. Skoring pada variabel sikap disebut positif apabila memiliki skor jawaban lebih dari 20 serta disebut negatif apabila skor jawaban kurang dari 20. Sedangkan pada variabel pengetahuan dan tindakan memiliki kategori baik apabila hasil skor 76\%-100\%, cukup hasil skor 56\%-75\%, dan kurang hasil skor $\leq 55 \%$ (Notoatmodjo, 2012).

Setelah pengolahan data, kemusian dilakukan pengelompokan menurut variabel bebas dan variabel terikat. Dimana variabel bebas adalah tingkat pengetahuan dan sikap, dan variable terikat adalah tindakan PHBS. Setelah itu dilakukan analisis data. Tujuan dari analisis data adalah melihat hubungan antara pengetahuan dan sikap dengan PHBS dari masyarakat di Kelurahan Ujung. Tahap selanjutnya adalah mengolah data dengan uji Spearman menggukan aplikasi di komputer. Penyajian data menggunakan tabel distribusi frekuensi serta presentase.

\section{HASIL DAN PEMBAHASAN}

Pada tabel 1 dapat dilihat bahwa sebagian besar responden termasuk pada kelompok umur 23-27 (32,4\%). Terciptanya seseorang melakukan perilaku PHBS di lingkungan keluarga yaitu salah satu faktor internalnya adalah umur. Semakin tua orang tersebut, semakin matang pemikiran dan pekerjaan seseorang, semakin dewasa ia jadinya (Hurlock, 2010).

Tabel 1. Karakteristik Responden Penelitian berdasarkan Umur, Pendidikan, dan Pekerjaan

\begin{tabular}{lll}
\hline Karakteristik & $\mathbf{n}$ & \% \\
\hline Umur (Tahun) & & 21,1 \\
$18-22$ & 15 & 32,4 \\
$23-27$ & 23 & 19,7 \\
$28-32$ & 14 & 14,1 \\
$33-37$ & 10 & 7,0 \\
$38-42$ & 5 & 1,4 \\
$43-47$ & 1 & 4,2 \\
$48-52$ & 3 & 14,1 \\
Pendidikan & & 56,3 \\
Tidak sekolah & 10 & 15,5 \\
Tamat SD & 40 & 12,7 \\
Tamat SMP & 11 & 1,4 \\
Tamat SMA & 9 & 81,7 \\
Tamat PT & 1 & 9,9 \\
Pekerjaan & & 7,0
\end{tabular}




\begin{tabular}{lll} 
Petani atau Buruh & 1 & 1,4 \\
\hline Total & 71 & 100 \\
\hline
\end{tabular}

Orang usia produktif lebih reseptif terhadap pengetahuan dibandingkan dengan usia non produktif, karena orang dewasa sudah mempunyai pengalaman yang mempengaruhi pola pikirnya (Notoadmodjo, 2012). Penelitian Kumbadewi (2016), menyebutkan bahwa usia memiliki pengaruh positif parsial terhadap produktivitas karyawan. Tingkat produktivitas pekerja meningkat karena pekerja berada pada usia produksi. Apabila pekerja mendekati usia tua, produktivitas kerja dari karyawan tersebut akan mengalami penurunan. Hal ini dikarenakan adanya keterbatasan dari faktor yang dapat memberikan pengaruh pada tubuh dan kesehatannya (Kumbadewi, Suwendra and Susila, 2016).

Penelitian Dharmawati (2016), menyatakan bahwa tidak ada hubungan antara usia dengan pengetahuan seseorang. Melalui pengetahuan sebelumnya, pengalaman sendiri, atau lingkungan dan faktor internal lainnya, pengetahuan seseorang dapat dibentuk untuk waktu yang lama dan akan berlanjut hingga tua (Dharmawati and Wirata, 2016). Umur memiliki impresi terhadap kapasitas pemahaman dan pola pikir seseorang. Seseorang dengan usia 20-35 tahun lebih memainkan peran yang aktif dalam kehidupan sosial dan lebih siap untuk mencoba beradaptasi dengan kesuksesan para lansia. Selain itu, mereka akan menghabiskan lebih banyak waktu untuk membaca. Menurut laporan, pada usia ini hampir tidak ada penurunan kecerdasan, pemecahan masalah, dan keterampilan ekspresi lisan (Notoatmodjo, 2014).

Penelitian ini menunjukkan hasil bahwa sebagian besar responden tamat SD yaitu sebanyak 40 responden $(56,3 \%)$. Dalam kehidupan sehari hari, Pendidikan merupakan faktor yang penting. Hal yang dapat dipengaruhi oleh tingkat Pendidikan adalah tanggapan seseorang tentang sesuatu yang bersifat kognitif. Pendidikan adalah sebuah upaya agar kelompok, masyarakat dan perseorangan mendapatkan dampak berupa tindakan agar dapat menyampaikan serta meluaskan pengetahuan. Hal ini dimaksudkan agar individu dan kelompok dapat menerapkan ilmu yang disampaikan oleh pendidik. Perilaku PHBS dapat dipengaruhi oleh pendidikan.

Berdasarkan penelitian Dharmawati (2016), mengatakan bahwa terdapat hubungan antara tingkat pendidikan dan pengetahuan seseorang. Dimana semakin seseorang memiliki tingkat Pendidikan yang tinggi maka informmasi yang diperoleh juga akan tinggi, sehingga pengetahuan yang dimiliki juga akan banyak. Sebaliknya apabila seseorang memiliki tingkat Pendidikan yang rendah akan dapat terhambat perkembangan sikap masyarakat untuk dapat menerima nilai-nilai serta informasi yang disampaikan (Dharmawati and Wirata, 2016). Penelitian lain juga sejalan, menyatakan bahwa ada hubungan antara tingkat pendidikan dengan Perilaku Hidup Bersih dan Sehat di kalangan ibu rumah tangga kampung Alang Pasaman Barat (Fersnandy, 2016).

Sebagian besar pekerjaan responden pada penelitian ini adalah adalah ibu rumah tangga, yakni 58 responden $(81,7 \%)$. Salah satu aktivitas penting yang dilaksanakan untuk mendukung kehidupan seseorang adalah pekerjaan. Pekerjaan yang berbeda akan mengacu pada tingkat pengetahuan yang berbeda pula. Hal ini selaras dengan bentuk dan tanggungan kerja dari pekerjaan tersebut. Penerapan kebiasaan PHBS di lingkungan rumah, akan dipengaruhi oleh pekerjaan yang dimiliki individu. Implementasi kebiasaan PHBS di lingkungan rumah tidak hanya dikoreksi dalam aspek fisik dan mental, namun juga dalam produktivitas. Penelitian yang dilakukan Usman, dkk (2020) menunjukkan bahwa ada pengaruh jenis pekerjaan terhadap pola PHBS. Semakin tinggi status sosial ekonomi keluarga antara pendidikan, pekerjaan dan status ekonomi secara umum, semakin baik perilaku hidup bersih dan sehat (Usman, Daud and Winarto, 2020).

Tabel 2. Karakteristik Responden berdasarkan Pengetahuan, Sikap, dan Tindakan Perilaku Hidup Bersih dan Sehat

\begin{tabular}{llc}
\hline Karakteristik & Frekuensi & \% \\
\hline Pengetahuan & & \\
\hline Baik & 13 & 18,3 \\
Cukup & 16 & 22,5 \\
Kurang & 42 & 59,2 \\
\hline Sikap & & \\
\hline Positif & 40 & 56,3 \\
Negatif & 31 & 43,7 \\
\hline Tindakan & & \\
\hline Baik & 18 & 50,4 \\
Cukup & 36 & 23,9 \\
Kurang & 17 & 100 \\
\hline Total & 71 &
\end{tabular}

Penelitian menunjukkan hasil bahwa, pengetahuan responden dikelompokkan dalam kategori baik, cukup, dan kurang. Tabel 2 menunjukkan hasil sebagian besar pengetahuan responden terkait PHBS berkategori kurang sebanyak 42 responden (59,2\%). Pengetahuan kurang pada responden berkaitan dengan penerapan PHBS di lingkungan keluarga. Prinsipnya keyakinan dapat diciptakan oleh pengetahuan sehingga keyakinan tersebut dapat 
diterapkan melalui perilaku yang cocok. Pengetahuan dipengaruhi oleh akses yang dimiliki seseorang terhadap informasi yang diperoleh dari berbagai hal (misalnya petugas kesehatan, buku bacaan, televisi, radio), dan kemudahan mengakses internet melalui telepon genggam (gadget) (Wulandini and Saputra, 2018).

Hasil penelitian sikap responden dikategorikan dalam kategori positif dan negatif. Tabel 2 menggambarkan hasil bahwa sebagian besar sikap responden terkait PHBS yaitu berkategori positif sebanyak 40 responden (56,3\%). Sikap responden menunjukkan positif terhadap penerapan perilaku PHBS di lingkungan rumah. Sikap merupakan sebuah respon dari individu terhadap rangsangan yang diterima oleh individu tersebut. Sikap adalah sebuah reaksi yang tidak ada hubungannya dengan seseorang serta belum mengarah pada sebuah tindakan (Notoatmodjo, 2014).

Tindakan responden dikategorikan dalam kategori baik, cukup, dan kurang. Tabel 2 menunjukkan hasil bahwa sebagian besar tindakan responden responden terkait perilaku PHBS berkategori cukup sebanyak 36 responden $(50,7 \%)$. Hasil penelitian menunjukkan bahwa mayoritas responden telah melakukan tindakan yang cukup untuk menerapkan perilaku PHBS di lingkungan rumah mereka.

Tindakan adalah hasil evaluasi rangsangan yang diketahui. Evaluasi tersebut kemudian diterapkan menjadi tindakan. Terdapat beberapa tingkatan dari sebuah tindakan meliputi persepsi, respon terpimpin, mekanisme serta adopsi (Notoatmodjo, 2014).

\section{Hubungan Pengetahuan dengan Tindakan PHBS}

Pada dasarnya, PHBS merupakan bentuk perilaku kesehatan yang nyata (Boekoesoe, Irwan and Yantu, 2018). Pengetahuan adalah hasil dari sebuah pemahaman, dimana pengetahuan merupakan kognitif dari sebuah konten yang pokok untuk penentuan perilaku (Fitriani, 2011). Perilaku yang sehat terbentuk dengan perngaruh dari ilmu serta pengalaman dari individu. Masyarakat yang memiliki Pendidikan yang tinggi lebih memiliki pemahaman tentang pentingnya Kesehatan. Dengan ilmu tersebut masyarakat dapat membuat lingkungan lebih sehat (Usman, Daud and Winarto, 2020).

Tabel 3. Hubungan Antara Pengetahuan Terhadap Tindakan Perilaku Hidup Bersih dan Sehat di Ujung Surabaya

\begin{tabular}{|c|c|c|c|c|c|c|c|c|c|}
\hline \multirow{3}{*}{ Pengetahuan } & \multicolumn{8}{|c|}{ Tindakan PHBS } & \multirow{3}{*}{$P$ Value } \\
\hline & \multicolumn{2}{|c|}{ Kurang } & \multicolumn{2}{|c|}{ Cukup } & \multicolumn{2}{|c|}{ Baik } & \multicolumn{2}{|c|}{ Total } & \\
\hline & $\mathbf{n}$ & $\%$ & $\mathbf{n}$ & $\%$ & n & $\%$ & n & $\%$ & \\
\hline Kurang & 17 & 41,5 & 22 & 53,7 & 2 & 4,9 & 41 & 100,0 & \\
\hline Cukup & 0 & 0,0 & 12 & 70,6 & 5 & 29,4 & 17 & 100,0 & 0,000 \\
\hline Baik & 0 & 0,0 & 2 & 15,4 & 11 & 84,6 & 13 & 100,0 & \\
\hline Total & 17 & 23,9 & 36 & 50,7 & 18 & 25,4 & 71 & 100,0 & \\
\hline
\end{tabular}

Tabel 3 menggambarkan bahwa mayoritas responden sebanyak 36 responden (50,7\%) memiliki tindakan yang cukup terhadap aplikasi perilaku hidup bersih dan sehat dalam lingkungan keluarga. Hasil penelitian menunjukkan responden memiliki pengetahuan yang kurang dengan tindakan yang cukup sebanyak 22 responden $(53,7 \%)$. Nilai $P$ Value yaitu $0,000<\alpha(0,05)$, sehingga $\mathrm{H}_{0}$ ditolak dengan correlation coefficient $\mathrm{p}=0,678$. Dapat diartikan bahwa terdapat hubungan dengan keeratan yang kuat antara pengetahuan dengan tindakan PHBS pada masyarakat yang tinggal di Kelurahan Ujung Kecamatan Semampir Kota Surabaya. Hasil penelitian menunjukkan bahwa mayoritas responden dengan pengetahuan serta tindakan yang cukup dalam pelaksanaan PHBS di tatanan rumah tangga.

Penelitian menunjukkan hasil bahwa jumlah ibu yang memberikan ASI Eksklusif di Kelurahan Ujung Kecamatan Semampir Kota Surabaya rendah. Hal ini dikarenakan pengetahuan ibu tentang pentingnya pemberian ASI Eksklusif rendah. Selain pemberian ASI Eksklusif yang rendah, capaian imunisasi dasar lengkap juga rendah karena masyarakat tidak secara rutin menimbang balita di posyandu serta dipengaruhi juga oleh kurangnya pengetahuan ibu tentang pentingnya imunisasi dan adanya anggapan yang salah tentang imunisasi. Sehingga dapat dikatakan responden tidak menerapkan PHBS apabila terdapat salah satu indicator PHBS yang tidak diterapkan.

Kondisi ini menunjukkan bahwa masyarakat di Kelurahan Ujung, Kecamatan Semampir, Kota Surabaya masih belum baik pelaksanaan PHBS di tatanan rumah tangga. Sehingga Dinas Kesehatan Kota Surabaya dan Puskesmas Sawah Pulo perlu melakukan Kerjasama untuk melaksanakan kegiatan penyuluhan kepada masyarakat tentang pentingnya PHBS. Selain itu juga perlu adanya kegiatan Emo-Demo mengenai PHBS agar pengetahuan masyarakat meningkat. Kegiatan Emo-Demo dan penyuluhan selanjutnya dapat diadopsi dan dilanjutkan oleh kader setempat dan menjadi inovasi dalam pemberian informasi tentang permasalahan kesehatan agar penerapan PHBS lebih baik.

Penelitian ini selaras dengan penelitian oleh Boekoesoe, yang menyatakan bahwa mayoritas masyarakat di pesisir desa Deme II menerapkan PHBS dengan kategori cukup sebanyak 43,5\%. Selain itu, penelitian Boekoesoe menyatakan bahwa pengetahuan dapat mempengaruhi Perilaku Hidup Bersih dan Sehat di lingkungan keluarga secara signifikan (Boekoesoe, Irwan and Yantu, 2018). Penelitian Chandra (2017), juga menyatakan bahwa 
terdapat hubungan yang signifikan antara pengetahuan dengan Perilaku Hidup Bersih dan Sehat siswa SDN Bantuil I (Chandra, Fauzan and Aquarista, 2017).

Penelitian ini sejalan dengan penelitian lain, dimana terdapat pengaruh antara pengetahuan terhadap PHBS masyarakat desa Pekonmon (Adliyani, Angraini and Soleha, 2017). Hasil penelitian lain di Kelurahan Rangkah Kota Surabaya menyatakan bahwa pengetahuan dapat mempengaruhi perilaku hidup bersih dan sehat secara signifikan (Wati and Ridlo, 2020).

Hasil penelitian ini juga selaras dan memperkuat hasil penelitian terdahulu dimana terdapat hubungan antara pengetahuan dengan penerapan perilaku hidup bersih dan sehat dalam tatana rumah tangga (Yuliandari and Herya, 2016). Akan tetapi, penelitian ini tidak sejalan dengan penelitian yang dilakukan oleh Bawole, dkk (2018), dimana dalam penelitian tersebut dikatakan bahwa tidak terdapat hubungan antara pengetahuan dan tindakan PHBS (Bawole, Umboh and Sumampouw, 2018).

Promosi kesehatan atau Pendidikan kesehatan yang memberikan informasi tentang kesehatan dapat dijadikan sebagai awal bagi seseorang untuk merubah perilaku kesehatan. Pendidikan kesehatan dapat berupa cara seseorang mendapatkan hidup yang sehat, bagaimana seseorang agar tetap sehat, serta bagaimana seseorang terhindar dari penyakit. Pendidikan kesehatan ini membuat pemahaman tentang kesehatan meningkat. Kemudian kesadaran pribadi akan muncul yang akhirnya akan terwujud sebuah perubahan perilaku dari pengetahuan tersebut. Mengubah tingkah laku dengan cara ini membutuhkan waktu yang lama, akan tetapi perubahan yang tercipta akan permanen, karena didasari oleh kesadaran (Agustini, 2019).

\section{Hubungan Sikap dengan Tindakan PHBS}

Sikap dapat dikatakan sebagai kecenderungan individu dalam bereaksi, tidak suka atau acuh tak acuh terhadap sesuatu, orang atau benda. Sikap adalah ekspresi emosional seseorang, yang mencerminkan suka atau tidak suka pada sesuatu (Damiati et al., 2017).

Variabel sikap responden terhadap tindakan PHBS dalam rumah tangga dikategorikan dalam dua kategori, yakni positif dan negatif. Responden yang bersikap positif terhadap tindakan PHBS di lingkungan rumah tangga sebanyak 40 orang $(56,3 \%)$.

Tabel 4. Hubungan Antara Sikap dengan Tindakan Perilaku Hidup Bersih dan Sehat di Ujung Surabaya

\begin{tabular}{|c|c|c|c|c|c|c|c|c|c|}
\hline \multirow{3}{*}{ Sikap } & \multicolumn{8}{|c|}{ Tindakan PHBS } & \multirow[t]{3}{*}{ Pvalue } \\
\hline & \multicolumn{2}{|c|}{ Kurang } & \multicolumn{2}{|c|}{ Cukup } & \multicolumn{2}{|c|}{ Baik } & \multicolumn{2}{|c|}{ Total } & \\
\hline & $\mathbf{n}$ & $\%$ & $\mathbf{N}$ & $\%$ & n & $\%$ & $\mathbf{n}$ & $\%$ & \\
\hline Positif & 0 & 0,0 & 22 & 55,0 & 18 & 45,0 & 40 & 100,0 & مOQ \\
\hline Negatif & 17 & 54,8 & 14 & 45,2 & 0 & 0,0 & 31 & 100,0 & 0,000 \\
\hline Total & 17 & 23,9 & 36 & 50,7 & 18 & 25,4 & 71 & 100,0 & \\
\hline
\end{tabular}

Tabel 4 menggambarkan bahwa mayoritas responden memiliki sikap yang positif dan tindakan yang cukup yakni sebanyak 22 responden $(55,0 \%)$. Nilai $\mathrm{p}$ adalah $0,000<\alpha(0,05)$ dengan correlation coefficient $\mathrm{p}=0,705$. Sehingga $\mathrm{H}_{0}$ ditolak, dapat dikatakan bahwa terdapat hubungan dengan keeratan yang kuat antara sikap dengan tindakan perilaku hidup bersih dan sehat di kalangan masyarakat Kelurahan Ujung, kecamatan Semampir Surabaya. Kondisi ini menunjukkan mayoritas responden mempunyai sikap serta tindakan yang cukup dalam penerapan PHBS di lingkungan keluarga, yaitu sebanyak 36 responden (50,7\%).

Berdasarkan hasil penelitian, masyarakat di Kelurahan Ujung Kecamatan Semampir Kota Surabaya cenderung bersikap positif terhadap PHBS, namun pada kenyataannya masih banyak masyarakat Kelurahan Ujung yang tidak melaksanakan PHBS dalam lingkungan keluarga. Penerapan PHBS yang kurang baik meliputi kurangnya kesadaran untuk melaksanakan imunisasi dasar lengkap pada bayi, karena terdapat budaya yang salah di masyarakat mengenai imunisasi. Budaya yang beredar ini membentuk sikap masyarakat terhadap imunisasi menjadi negatif. Sikap negatif adalah respon seseorang untuk menghindari, menjauhi, membenci serta tidak suka terhadap hal tersebut. Sikap positif seseorang terhadap sebuah nilai-nilai kesehatan tidak selalu ditunjukkan dalam sebuah tindakan yang nyata (Wawan and M., 2018). Penelitian yang dilakukan oleh Azam, menunjukkan bahwa siswa dengan sikap positif lebih cenderung mencuci tangan pakai sabun (Azam, Sumardiyono and Murti, 2016).

Sejalan dengan penelitian oleh Rayhana, yang menunjukkan hubungan antara sikap ibu rumah tangga di Bekasi Utara dengan PHBS di tatanan rumah tangga (Rayhana and Rini Astin, 2016). Penelitian ini sejalan dengan Penelitian di SDN 25 Kabupaten Sintang, dimana terdapat hubungan antara sikap siswa dengan PHBS di sekolah (Kwureh, 2016). Hasil serupa juga ditunjukkan oleh penelitian yang dilakukan di SDN 08 Kabupaten Konawe Selatan yaitu ada hubungan sikap anak usia sekolah dasar dengan PHBS di sekolah (Kanro, Yasnani and Saptaputra, 2017).

Pemahaman tentang sikap, dimana sikap adalah suatu kecenderungan agar seseorang melakukan tindakan mendukung hubungan antara sikap dan pelaksanaan PHBS (Chandra, Fauzan and Aquarista, 2017). Sikap kesehatan adalah tanggapan perasaan atau keyakinan seseorang dalam hal perasaan, pikiran, dan kerentanan 
terhadap informasi kesehatan. Perasaan itu akan membuat masyarakat cenderung merespon dengan baik atau memiliki perilaku yang positif (Azam, Sumardiyono and Murti, 2016).

Terdapat tiga komponen dari sikap. Komponen pertama adalah kognitif, dimana kognitif merupakan apa yang diyakini seseorang dalam sikapnya. Kognitif cenderung menimbulkan kontroversi. Komponen kedua adalah afektif, dimana afektif cenderung pada sesuatu yang emosional. Komponen afektif merupakan pengaruh paling kuat yang dapat merubah sikap. Komponen ketiga adalah konatif. Komponen afektif lebih mengarah kepada perilaku yang berdasar pada sikap dari individu tersebut. Sikap tersebut membuat seseorang cenderung melakukan sesuatu dengan cara tertentu (Azwar, 2013).

Penelitian yang sudah dilakukan di RW 9 Kelurahan Ujung, Kecamatan Semampir, Kota Surabaya terkait pengetahuan dengan tindakan PHBS didapatkan hasil nilai $P$ Value yaitu $0,000<\alpha(0,05)$, sehingga $\mathrm{H}_{0}$ ditolak, artinya terdapat hubungan antara pengetahuan dengan tindakan PHBS pada masyarakat di Kelurahan Ujung. Hasil penelitian terkait sikap dan tindakan PHBS didapatkan hasil nilai $P$ Value yaitu $0,000<\alpha(0,05)$, sehingga $\mathrm{H}_{0}$ ditolak, artinya terdapat hubungan antara sikap dengan tindakan PHBS pada masyarakat di Kelurahan Ujung Kecamatan Semampir Kota Surabaya.

\section{KESIMPULAN}

Kesimpulan penelitian yang dilakukan di RW 9 Kelurahan Ujung, Kecamatan Semampir, Kota Surabaya, maka disimpulkan bahwa adanya hubungan antara pengetahuan dan sikap masyarakat RW 9 Kelurahan Ujung terhadap tindakan PHBS dalam tatanan rumah tangga. Pengetahuan tentang nilai kesehatan di dalam keluarga adalah menjadi komponen yang penting untuk meningkatkan derajat kesehatan pada tatanan rumah tangga, terutama dalam berperilaku hidup bersih dan sehat. Sikap individu dalam menyikapi atau merespon tentang kesehatan juga diperlukan untuk menciptakan tindakan kesehatan yang maksimal.

Perlu adanya kerja sama antara Dinas Kesehatan Kota Surabaya dengan Puskesmas Sawah Pulo untuk meningkatkan penyuluhan dan kegiatan emo demo tentang PHBS. Tujuannya adalah untuk meningkatkan derajat pengetahuan kesehatan masyarakat. Keberlanjutan kegiatan penyuluhan dan emo demo dapat diadopsi dan menjadi inovasi bagi kader. Kader dapat memberikan informasi mengenai permasalahan kesehatan dalam merubah perilaku hidup bersih dan sehat yang lebih baik lagi pada masyarakat Kelurahan Ujung.

\section{REFERENSI}

Adliyani, Z. O. N., Angraini, D. I. and Soleha, T. U. (2017) 'Pengaruh Pengetahuan, Pendidikan dan Ekonomi terhadap Perilaku Hidup Bersih dan Sehat pada Masyarakat Desa Pekonmon Kecamatan Ngambur Kabupaten Pesisir Barat', Majority Journal, 7(1), pp. 6-13.

Adnani, H. (2011) Ilmu Kesehatan Masyarakat. Yogyakarta: Nuha Medika.

Agustini, N. N. S. (2019) TINGKAT PENGETAHUAN KESEHATAN GIGI DAN MULUT SERTA PERILAKU MENYIKAT GIGI SISWA KELAS V SDN 3 BATUBULAN TAHUN 2019. Poltekkes Kemenkes Denpasar.

Azam, A. M., Sumardiyono and Murti, B. (2016) 'Hubungan Tingkat Pengetahuan, Sikap Terhadap Perilaku Cuci Tangan Pakai Sabun ( CTPS ) Pada SMPN 1 Surakarta dan SMPN 6 Surakarta', Nexus Kedokteran Komunitas, 5(2), pp. 1-10.

Azwar, S. (2013) 'Sikap Manusia: Teori dan Pengukurannya', Sikap Manusia: Teori dan Pengukurannya.

Badan Penelitian dan Pengembangan Kesehatan (2019a) 'Laporan Nasional RISKESDAS 2018', Badan Penelitian dan Pengembangan Kesehatan. Jakarta: Lembaga Penerbit Badan Penelitian dan Pengembangan Kesehatan, p. 628

Badan Penelitian dan Pengembangan Kesehatan (2019b) Laporan Provinsi Jawa Timur Riskesdas 2018, Kementerian Kesehatan RI. Jakarta: Lembaga Penerbit Badan Penelitian dan Pengembangan Kesehatan.

Bawole, B. B., Umboh, J. M. L. and Sumampouw, O. J. (2018) 'Hubungan Antara Tingkat Pengetahuan Dan Sikap Dengan Tindakan Perilaku Hidup Bersih Dan Sehat Pada Murid Sekolah Dasar GMIM 9 Dan Sekolah Dasar Negeri Inpres Pinangunian Kota Bitung', Kesmas, 7(5).

BKKBN et al. (2018) Survei Demografi dan Kesehatan Indonesia 2017. Jakarta: Badan Kependudukan dan Keluarga Berencana Nasional.

Boekoesoe, L., Irwan and Yantu, R. R. V. M. (2018) 'PERILAKU HIDUP BERSIH DAN SEHAT PADA TATANAN RUMAH TANGGA DITINJAU DARI ASPEK PENGETAHUAN DAN STATUS EKONOMI MASYARAKAT', 2, p. 17. doi: https://doi.org/10.35971/gojhes.v2i2.5268.

Chandra, Fauzan, A. and Aquarista, M. F. (2017) 'HUBUNGAN ANTARA PENGETAHUAN DAN SIKAP DENGAN PERILAKU HIDUP BERSIH DAN SEHAT (PHBS) PADA SISWA SEKOLAH DASAR (SD) DI KECAMATAN CERBON TAHUN 2016', Jurnal Kesehatan Masyarakat Khatulistiwa, 4(3).

Damiati et al. (2017) Perilaku Konsumen. 1st edn. Depok: PT Raja Grafindo Persada.

Dharma, K. K. (2011) Metodologi Penelitian Keperawatan. Jakarta: CV Trans Info Media.

Dharmawati, I. G. A. A. and Wirata, I. N. (2016) 'Hubungan Tingkat Pendidikan, Umur, Dan Masa Kerja Dengan Tingkat Pengetahuan Kesehatan Gigi Dan Mulut Pada Guru Penjaskes Sd Di Kecamatan Tampak Siring 
Gianyar', Jurnal Kesehatan Gigi.

Dinas Kesehatan Kota Surabaya (2019) 'Profil Kesehatan Kota Surabaya 2018'.

Fersnandy, R. (2016) 'HUBUNGAN PENGETAHUAN, SIKAP DAN TINGKAT PENDIDIKAN DENGAN PERILAKU HIDUP BERSIH DAN SEHAT PADA IBU RUMAH TANGGA DI JORONG KAMPUNG ALANG PASAMAN BARAT'.

Fitriani, S. (2011) Promosi Kesehatan Edisi 1. Yogyakarta: Graha Ilmu.

Hurlock, E. (2010) Psikologi Perkembangan Suatu Pendekatan Sepanjang Rentang Hidup., Erlangga.

Kanro, R., Yasnani, Y. and Saptaputra, S. (2017) 'FAKTOR-FAKTOR YANG BERHUBUNGAN DENGAN PERILAKU HIDUP BERSIH DAN SEHAT PADA ANAK USIA SEKOLAH DASAR NEGERI 08 MORAMO UTARA DESA WAWATU KECAMATAN MORAMO UTARA KABUPATEN KONAWE SELATAN TAHUN 2016', Jurnal Ilmiah Mahasiswa Kesehatan Masyarakat Unsyiah.

Kementerian Kesehatan RI (2011) 'Pedoman Pembinaan Perilaku Hidup Bersih dan Sehat', in Peraturan Menteri Kesehatan Republik Indonesia nomor: 2269/MENKES/PER/XI/2011 Pedoman pembinaan perilaku hidup bersih dan sehat (PHBS). KEMENTERIAN KESEHATAN RI.

Kementerian Kesehatan RI (2016) PHBS, Kementerian Kesehatan Direktorat Promosi Kesehatan dan Pemberdayaan Masyarakat. Available at: http://promkes.kemkes.go.id/phbs.

Kumbadewi, L. S., Suwendra, I. W. and Susila, G. P. A. J. (2016) 'PENGARUH UMUR, PENGALAMAN KERJA, UPAH, TEKNOLOGI DAN LINGKUNGAN KERJA TERHADAP PRODUKTIVITAS KARYAWAN', Bisma Universitas Pendidikan Ganesha, 4.

Kusumawardani, N. (2018) 'Gambaran Masalah Perilaku Hidup Bersih dan Sehat Masyarakat Indonesia'. Badan Litbangkes.

Kwureh, H. N. (2016) 'HUBUNGAN JENIS KELAMIN, PENGETAHUAN, SIKAP DAN PERAN GURU DENGAN PERILAKU HIDUP BERSIH DAN SEHAT PADA SISWA SD NEGERI 25 BEGORI KECAMATAN SERAWAI KABUPATEN SINTANG', Wawasan Kesehatan.

Notoadmodjo, S. (2012) Pendidikan Kesehatan dan Perilaku Kesehatan Edisi 2012, Rineka Cipta.

Notoatmodjo, S. (2012) 'Metodologi Penelitian Kesehatan', in. Jakarta: Rineka Cipta.

Notoatmodjo, S. (2014) Ilmu Perilaku Kesehatan. Jakarta: Rineka Cipta.

Rayhana and Rini Astin, T. (2016) 'Hubungan Karakteristik, Pengetahuan dan Sikap terhadap Perilaku Hidup Bersih dan Sehat pada Ibu Rumah Tangga di Kelurahan Kebalen Kecamatan Babelan Bekasi Utara', Jurnal Kedokteran dan Kesehatan.

Usman, R., Daud, F. and Winarto, M. (2020) 'Hubungan Status Sosial Ekonomi dengan Perilaku Hidup Bersih Sehat (PHBS) Masyarakat di Desa Pajukukang Kabupaten Maros', Biology Teaching and Learning, 3, pp. $15-23$.

UU RI (2009) 'UU RI No 36 Tentang Kesehatan', UU RI No 362009.

Wati, P. D. C. A. and Ridlo, I. A. (2020) 'Hygienic and Healthy Lifestyle in the Urban Village of Rangkah Surabaya', Jurnal PROMKES, 8(1), p. 47. doi: 10.20473/jpk.v8.i1.2020.47-58.

Wawan, A. and M., D. (2018) Teori dan Pengukuran Pengetahuan, Sikap, dan Perilaku Manusia Cetakan IV. Yogyakarta: Nuha Medika.

Wulandini, P. and Saputra, R. (2018) 'Faktor-Faktor Yang Berhubungan Dengan Perilaku Hidup Bersih Dan Sehat (PHBS) Di Desa Kualu Kecamatan Tambang Kampar’, Photon: Jurnal Sain dan Kesehatan, 8(2), pp. 121128. doi: 10.37859/jp.v8i2.725.

Yuliandari, D. W. and Herya, N. (2016) 'Pengaruh Pengetahuan Dan Sosial Ekonomi Keluarga Terhadap Penerapan Perilaku Hidup Bersih Dan Sehat (Phbs) Tatanan Rumah Tangga Di Wilayah Kerja Puskesmas X Kota Kediri Relationship of Knowledge and Socio-Economic of Family With Clean and Healthy Behaviou', pp. 17-22. 